\title{
Effect of bovine ampullary and isthmic oviductal fluid on motility, acrosome reaction and fertility of bull spermatozoa
}

\author{
A. A. Grippo, A. L. Way and G. J. Killian* \\ Dairy Breeding Research Center, Department of Dairy and Animal Science. The Pennsylvania State \\ University, University Park, PA 16802, USA
}

\begin{abstract}
Motility, acrosome reaction and oocyte fertilizing ability were assessed for bull spermatozoa after incubation in regional (isthmic or ampullary), bovine oviductal fluid, pooled by stage of the oestrous cycle. Oviductal fluids collected daily from isthmic and ampullary cannulae implanted in the same oviduct were divided into pools, representing two oestrous cycle stages, based on daily serum progesterone concentrations. Ejaculated bull spermatozoa were incubated for $0-6 \mathrm{~h}$ in each type of oviductal fluid. Incubation in isthmic oviductal fluid collected during the nonluteal stage, including oestrus and ovulation, decreased overall sperm motility (from $71.7 \%$ motile spermatozoa to $34.0 \%$ ) and both path (78 $\mu \mathrm{m} \mathrm{s}^{-1}$ versus $\left.86-89 \mu \mathrm{m} \mathrm{s}^{-1}\right)$ and progressive $\left(74 \mu \mathrm{m} \mathrm{s}^{-1}\right.$ versus $83-85 \mu \mathrm{m} \mathrm{s}^{-1}$ ) velocities of spermatozoa motion. Spermatozoa incubated in isthmic, non-luteal oviductal fluid had a higher rate and extent of sperm acrosome reaction (213\% of control versus $136-161 \%$ of control by $2 \mathrm{~h}$ incubation) compared with spermatozoa incubated in other oviductal fluid types. However, incubation in nonluteal ampullary fluid increased the number of spermatozoa, which were both acrosome reacted and live, and able to fertilize bovine ova ( $88.7 \%$ fertilized versus $75-81 \%$ ). Glycosaminoglycan concentrations were similar among types of oviductal fluid $\left(0.77-0.88 \mathrm{mg} \mathrm{ml}^{-1}\right)$. These findings indicate that oviductal fluid differentially affects sperm function, depending on the oviduct region and the stage of the oestrous cycle at which the fluid was obtained.
\end{abstract}

\section{Introduction}

The mammalian oviduct provides the environment for gamete transport and for events leading to fertilization. The epithelium lining the oviduct and its secretory products appear to influence the functions of spermatozoa, ova and embryos. Oviductal fluid contained within the lumen is a product of both serum transudate and active secretion from the epithelium (Leese, 1988). It is well documented that secretions of oviduct epithelial cells differ with the stage of the oestrous cycle (Mastroianni et al., 1961; Restall, 1966; Malayer et al., 1988; Buhi et al., 1989; Killian et al., 1989; Verhage et al., 1989; Boice et al., 1990; Gerena and Killian, 1990; Grippo et al., 1992). Because the composition of oviductal fluid collected at different stages of the oestrous cycle varies, it is likely that its effects on the gametes vary during the course of the cycle.

There is also evidence that the effects of the oviduct on sperm function differ with oviductal region. The oviductal isthmus may serve as a sperm reservoir, where it is likely that capacitation occurs (First and Parrish, 1987). In cattle, spermatozoa are retained in the isthmus for up to $20 \mathrm{~h}$ (Hunter and Wilmut, 1984). Because the ampulla is the likely site of fertilization, spermatozoa in the ampulla must be both capacitated and induced to undergo the acrosome reaction to penetrate the ovum.

${ }^{*}$ Correspondence and reprint requests.

Received 13 March 1995.
Despite the potential importance of the oviduct in determining the success of fertilization, relatively little is known of how it affects sperm function, and how its effects may vary with oviduct region and stage of the oestrous cycle. A modification of surgical methods developed in our laboratory (Kavanaugh and Killian, 1988; Kavanaugh et al., 1992) has enabled collection of oviductal fluid from both the isthmus and ampulla of the same oviduct. The goal of this study was to compare the effects of fluids collected from different oviduct regions and oestrous cycle stages on bull sperm motility, acrosome reaction and the ability of spermatozoa to fertilize bovine oocytes in vivo.

\section{Materials and Methods}

\section{Oviductal fluid collection and storage}

Fluid was collected from cannulated oviducts of ten cows as described by Kavanaugh and Killian (1988) and Kavanaugh et al. (1992). Fluid was collected from both the isthmus and ampulla during a single cycle of each cow, and daily samples were combined into nonluteal or luteal pools. Stages of the oestrous cycle were defined by serum progesterone concentrations determined by radioimmunoassay on daily serum samples as described by Killian et al. (1989). The luteal stage consisted of days when serum progesterone was $\geq 1.5 \mathrm{ng}$ $\mathrm{ml}^{-1}$. The nonluteal stage comprised days of oestrus and 
ovulation and the two subsequent days. Oestrus was assumed to be 4 days before the initial rise in serum progesterone, following a period when progesterone concentrations were $<1.5 \mathrm{ng} \mathrm{ml}^{-1}$. Ovulation was assumed to occur on the day after oestrus. To support comparisons of oviductal fluid from clearly defined luteal with that from ovulatory stages, oviductal fluid collected when serum progesterone was $<1.5 \mathrm{ng} \mathrm{ml}^{-1}$, but before the day of ovulation, was not analysed. Stages were assigned on the basis of observations of behavioural oestrus made in the original study (Killian et al., 1989). The osmolality of oviductal fluid for nonluteal and luteal pools was: $269.2 \pm 11.3$ (ampullary, nonluteal); 265.3 \pm 8.7 (ampullary, luteal); $267.7 \pm 8.7$ (isthmic, nonluteal); and $263.5 \pm 46.1$ (isthmic, luteal).

\section{Procedures for assessing sperm function}

Collection of spermatozoa. Modifications of the method of Parrish et al. (1988), as described by McNutt and Killian (1991), were used to determine the effect of oviductal fluid on sperm motility, viability, capacitation and the acrosome reaction. Briefly, ejaculated semen was collected from three bulls previously selected for similar rates of acrosome reaction in response to heparin capacitation and acrosome reaction induction with lysophosphatidylcholine (Parrish et al., 1988). Spermatozoa were washed twice by centrifugation (10 $\mathrm{min}, 500 \mathrm{~g}$ ) in protein-free, modified Tyrode's medium containing $1 \mathrm{mg}$ polyvinyl alcohol $\mathrm{ml}^{-1}$ (Bavister, 1981; Parrish et al,, 1988), and the sperm pellet was diluted with modified Tyrode's medium to its original volume. Concurrently, incubation tubes were prepared with $20 \%$ oviductal fluid $/ 80 \%$ modified Tyrode's medium ( $\mathrm{v} / \mathrm{v})$ or $40 \%$ oviductal fluid $/ 60 \%$ modified Tyrode's medium $(\mathrm{v} / \mathrm{v})$, and equilibrated in a $5 \% \mathrm{CO}_{2}$ humidified incubator at $39^{\circ} \mathrm{C}$ for approximately $30 \mathrm{~min}$. Preliminary experiments showed that concentrations of oviductal fluid higher than $40 \%$ resulted in background staining too intense to assess acrosome reaction accurately. Spermatozoa were also incubated in heparin ( $\left.10 \mu \mathrm{g} \mathrm{ml}{ }^{-1}\right)$ and modified Tyrode's medium alone (blank controls). Controls confirmed day to day replicability, and substantiated the ability of the spermatozoa to undergo capacitation and the acrosome reaction. Three replicate experiments were performed using spermatozoa from 12 bulls and oviductal fluid from ten cows.

Percentage motility, acrosome reaction and viability. An aliquot of sperm suspension was added to each incubation tube containing oviductal fluid or control medium to yield a final concentration of $50 \times 10^{6}$ spermatozoa ml ${ }^{-1}$, and incubated at $39^{\circ} \mathrm{C}$ under $5 \% \mathrm{CO}_{2}$ in air. At $0,2,4$ and $6 \mathrm{~h}$, the incubation tubes were gently but thoroughly mixed, and a slide was prepared to determine the percentage of motile spermatozoa by subjective evaluation of four fields under a microscope. The percentage of acrosome reacted spermatozoa in the first two replicates was assessed by smearing an aliquot from each reaction tube on a slide and drying and staining it with naphthol yellow-erythrosin B (Lenz et al., 1982) and the number of acrosome reacted spermatozoa per 100 spermatozoa was counted. Eosin B-aniline blue stain in phosphate buffer was used to determine the viability of each sperm sample in the third replicate experiment (Shaffer and Almquist, 1948). An aliquot of $5 \mu \mathrm{l}$ was removed from each tube to a slide, mixed with stain, smeared and dried under a warm air current. Overall viability was determined by the number of live spermatozoa per 100 spermatozoa counted. The viability of acrosomereacted spermatozoa, defined as the number of live or number of dead acrosome-reacted spermatozoa per 100 counted, was also assessed by eosin B-aniline blue staining (Way et al., 1995). No significant differences were found between the naphthol yellow-erythrosin B and eosin B-aniline blue stains for acrosome-reacted populations of ejaculated spermatozoa capacitated with heparin (Way et al., 1995). At 0, 2, 4 and $6 \mathrm{~h}$ after addition of spermatozoa, $\mathrm{pH}$ remained at $7.4-7.6$ for all $40 \%$ nonluteal oviduct fluid incubation tubes.

Analysis of sperm motility. A sample from each incubation tube containing spermatozoa from two of the bulls incubated in luteal or nonluteal oviductal fluid from three cows was subjected to motion analysis. At the initial time point, these aliquots were diluted to $12.5 \times 10^{6}$ spermatozoa $\mathrm{ml}^{-1}$, and $4 \mu \mathrm{l}$ was pipetted onto each of three warmed Helber chambers (C. A. Hausser and Sons, Philadelphia, PA). Start times were staggered, allowing time for dilution, slide preparation and videotaping, to maintain a true zero time for each sample, and assessments were made at 0,2 and $4 \mathrm{~h}$. Videotapes of spermatozoa on each Helber chamber were prepared as described by McNutt et al., 1994, and analysed by a Hamilton Thorn motion analyser (Hamilton Thorn Research Inc., Danvers, MA), connected to a Panasonic 3000 video recorder. From one to 20 spermatozoa were analysed per field scanned, with each scan set to acquire 20 sequential frames at $30 \mathrm{~s}^{-1}$. Spermatozoa that collided or were agglutinated were not included in the analysis. The total number of spermatozoa analysed per treatment (two bulls $\times$ three cows) ranged from 67 to 361 . Fewer spermatozoa were analysed at $4 \mathrm{~h}$ because of agglutination.

Calculations of sperm movement by the motion analyser were based on the cell centre of brightness of each frame, which was used to measure several motion parameters, ALH, BCF, VSL, VCL, VAP, STR and LIN, which are defined in Table 1 .

\section{In vitro fertilization techniques}

Bovine in vitro fertilization techniques were based on those reported by Parrish et al. (1988) and Bavister et al. (1983). Collection of ovaries, ova recovery and fertilization procedures are described by McNutt and Killian (1991). Briefly, oocytes were collected by syringe aspiration from ovaries obtained from an abattoir. Aspirated oocytes and follicular fluid were collected in $15 \mathrm{ml}$ conical tubes, and allowed to settle for $30 \mathrm{~min}$. Under a microscope, oocytes with an intact, compact cumulus were selected and washed three times in lowbicarbonate-Hepes medium. Cumulus-oocyte complexes were matured in vitro in groups of $10-15$ per $50 \mu$ drop of maturation medium (TCM-199 medium supplemented with LH, FSH, oestradiol, heat-inactivated fetal calf serum, pyruvate and gentamycin). Mature oocytes, with expanded cumulus, evenly granulated cytoplasm and apparent polar body, were observed after $22-24 \mathrm{~h}$ incubation at $39^{\circ} \mathrm{C}$ in a $5 \% \mathrm{CO}_{2}$ humidified incubator. 
Table 1. Definitions of motility parameters of the Hamilton Thorn Motion Analyser

\begin{tabular}{|c|c|c|c|}
\hline Abbreviation & Parameter & Units & Definition \\
\hline $\mathrm{ALH}$ & Lateral head displacement & $\mu \mathrm{m}$ & Mean width of spermatozoa head oscillation \\
\hline $\mathrm{BCF}$ & Beat cross frequency & $\mathrm{Hz}$ & Frequency that spermatozoa track ${ }^{1}$ crosses spermatozoa path $^{2}$ \\
\hline VSL & $\begin{array}{l}\text { Straight line velocity (or progressive } \\
\text { velocity) }\end{array}$ & $\mu \mathrm{ms}^{-1}$ & $\begin{array}{l}\text { Straight line distance from beginning to end of spermatozoa } \\
\text { track divided by time elapsed }\end{array}$ \\
\hline VCL & Curvilinear velocity (or track speed) & $\mu \mathrm{m} \mathrm{s}^{-1}$ & $\begin{array}{l}\text { Total distance between each measured position of } \\
\text { spermatozoa track divided by time elapsed }\end{array}$ \\
\hline VAP & Path velocity & $\mu \mathrm{m} \mathrm{s}{ }^{-1}$ & $\begin{array}{l}\text { Total average path distance }{ }^{3} \text { for each spermatozoon divided } \\
\text { by time elapsed }\end{array}$ \\
\hline LIN & Linearity & $\%$ & Degree of departure from linear progression = VSL $/ \mathrm{VCL}$ \\
\hline STR & Straightness & $\%$ & VSL/VAP \\
\hline
\end{tabular}

'The Hamilton-Thorn Motion Analyser calculates a cell centre of brightness for each frame (up to 30 frames $\mathrm{s}^{-1}$ ), allowing a very close approximation to the position of the centre of mass of the sperm cell. Cells are tracked by comparing successive frames. A track is formed by joining the positions between succeeding frames with straight lines. This is therefore an electronic interpretation of the actual spermatozoan path.

${ }^{2}$ The actual path of the spermatozoa.

${ }^{3}$ A five-point running average position rate of change, giving a smoothed cell path velocity. It is the total distance along the average path for each sperm cell, divided by the time elapsed.

Spermatozoa used for insemination were prepared as described for the acrosome reaction experiment above, with $40 \%$ oviductal fluid-modified Tyrode's medium ( $\mathrm{v} / \mathrm{v}$ ) only, or with heparin. For this experiment, spermatozoa were incubated for $5 \mathrm{~h}$ in isthmic or ampullary oviductal fluid collected from three cows during nonluteal or luteal stages. Mature, cumulusintact ova were washed three times in low bicarbonate-Hepes medium (Bavister, 1983) and 8-12 ova were transferred to each $50 \mu \mathrm{l}$ fertilization medium microdrop. Spermatozoa previously incubated in oviductal fluid $\left(2.5 \times 10^{5}\right)$ were added and coincubated with ova for an additional $16-18 \mathrm{~h}$ at $39^{\circ} \mathrm{C}, 5 \% \mathrm{CO}_{2}$. Penicillamine/hypotaurine/epinephrine solution was not added.

After coincubation, oocytes were removed from microdrops and washed. Cumulus was removed by passage through a 30 gauge needle. Oocytes were placed on a microscope slide with a minimal volume of low bicarbonate-Hepes medium. Oocytes were fixed in acid:alcohol (3:1 glacial acetic acid:95\% $(\mathrm{v} / \mathrm{v})$ ethanol) for at least $24 \mathrm{~h}$, and stained with $1 \%(\mathrm{w} / \mathrm{v})$ aceto-orcein (Sirard et al., 1988) just before evaluation under a microscope. Oocytes were considered fertilized if either two polar bodies were observed, or pronuclear chromatin was observed in a mitotic stage.

\section{Analysis of total glycosaminoglycans}

The colorimetric method of Kubajak and Ax (1985), based on that of Whiteman (1973) using Alcian blue dye, was used to determine total glycosaminoglycan concentration. Isthmic and ampullary oviductal fluids collected from four cows were analysed during nonluteal and luteal stages.

\section{Statistical analyses}

For each time point, the effect of region and oestrous cycle stage of oviductal fluid on motility, viability, glycosaminoglycan concentration, or each motion parameter $(A L H, B C F$, LIN, STR, VAP, VCL, VSL) was determined using general linear models analysis of variance (SAS, 1988). Fisher's protected least significant differences test was used to test the significance of bull, cow, region (ampulla or isthmus) and stage (nonluteal or luteal), as well as bull by cow and region by stage interactions. Comparisons were considered for region within stage and stage within region only. Significance with respect to pair-wise comparisons (region within stage or stage within region) were also noted for the motion analysis results.

The acrosome reaction data from three replicate experiments were standardized by expressing data as percentages of control values. For each time point in each experiment, the nonheparin-treated control spermatozoa (in modified Tyrode's medium) were assessed for acrosome reaction, or for acrosomereacted live and acrosome-reacted dead spermatozoa. Means of these control values were divided into each data point and multiplied by 100 to calculate a percentage of the control value. This value was then used to analyse the effect of region and oestrous cycle stage of oviductal fluid on acrosomereacted, acrosome-reacted live or acrosome-reacted dead spermatozoa, using general linear models analysis of variance. Fisher's protected least significant differences test was used to test the significance of region, stage and region by stage interactions. Comparisons were considered for region within stage and stage within region only.

General linear models analysis was also used to compare the effect of spermatozoa incubated in oviductal fluid from two regions and two oestrous cycle stages on fertilization success. Tukey's Studentized range test was used to compare region within stage and stage within region only. Fertilization success of spermatozoa incubated with regional, stage-pooled oviductal fluid was compared with spermatozoa incubated with heparin by Student's $t$ test. Significance was accepted as $P \leq 0.05$ for all analyses.

\section{Results}

No differences in sperm viability, as analysed by eosin B-aniline blue stain, were found among oviductal fluid Downloaded from Bioscientifica.com at 04/26/2023 12:43:12PM 


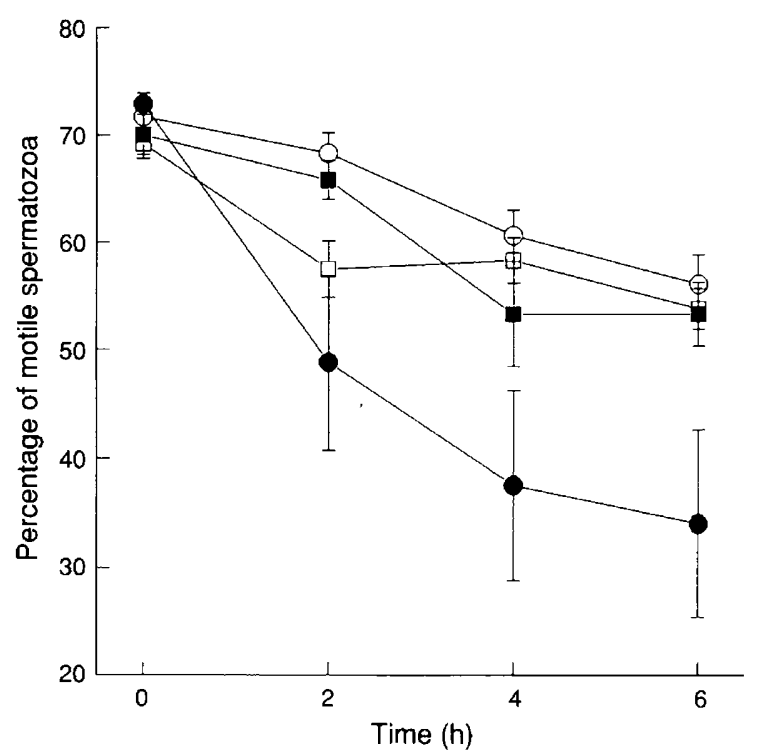

Fig. 1. Effect of oviductal fluid on sperm motility (mean \pm SEM). Spermatozoa were incubated for $0,2,4$ or $6 \mathrm{~h}$ in $40 \%$ oviductal fluid collected from ampullary (squares) or isthmic (circles) regions from four cows during luteal (open) or nonluteal (closed) cycle stages. Sperm motility was assessed visually by a trained observer for the percentage of motile spermatozoa in each field; at least four fields per slide were measured. Significant differences were observed at: $2 \mathrm{~h}$, ampullary nonluteal $>$ isthmic nonluteal $(P=0.046)$, isthmic luteal $>$ isthmic noniuteal $(P=0.023) ; 4 \mathrm{~h}$ isthmic luteal $>$ isthmic nonluteal $(P=0.029) ; 6 \mathrm{~h}$ ampullary nonluteal $>$ isthmic nonluteal $(P=0.028)$, isthmic luteal $>$ isthmic nonluteal $(P=0.010)$.

treatments, or between oviductal fluid-treated and untreated control spermatozoa, over the $6 \mathrm{~h}$ incubation.

No differences were observed in sperm motility or acrosome reaction for incubation including $20 \%$ oviductal fluid. The percentage of motile spermatozoa did not differ with $40 \%$ oviductal fluid treatment at the first time point (Fig. 1). For the remainder of the $6 \mathrm{~h}$ incubation, isthmic nonluteal oviductal fluid suppressed motility significantly compared with incubation with other oviductal fluids.

Significant differences were observed in several motion parameters after incubation of spermatozoa with isthmic versus ampullary with $40 \%(\mathrm{v} / \mathrm{v})$ oviductal fluid (Figs 2, 3). Regional effects were noted in lateral head movement and linearity in spermatozoa incubated for $2 \mathrm{~h}$, and in straightness after $4 \mathrm{~h}$ incubation in oviductal fluid. Lateral head movement was greater $(P=0.0342)$ for spermatozoa incubated for $2 \mathrm{~h}$ in isthmic fluid compared with ampullary, while linearity was greater $(P=0.0051)$ after incubation for $2 \mathrm{~h}$ in ampullary fluid. Spermatozoa incubated in ampullary fluid for $4 \mathrm{~h}$ showed greater straightness than did spermatozoa incubated in isthmic fluid. Incubation for $2 \mathrm{~h}$ in luteal oviductal fluid resulted in greater average path velocity and curvilinear velocity compared with incubation in nonluteal oviductal fluid. When pair-wise comparisons are considered (stage within region or region within stage), spermatozoa incubated in isthmic oviductal fluid collected during the nonluteal stage demonstrated minimal lateral head movement, linearity, straightness, path velocity, curvilinear velocity and straightline velocity compared with other types of fluids (Table 2 ).

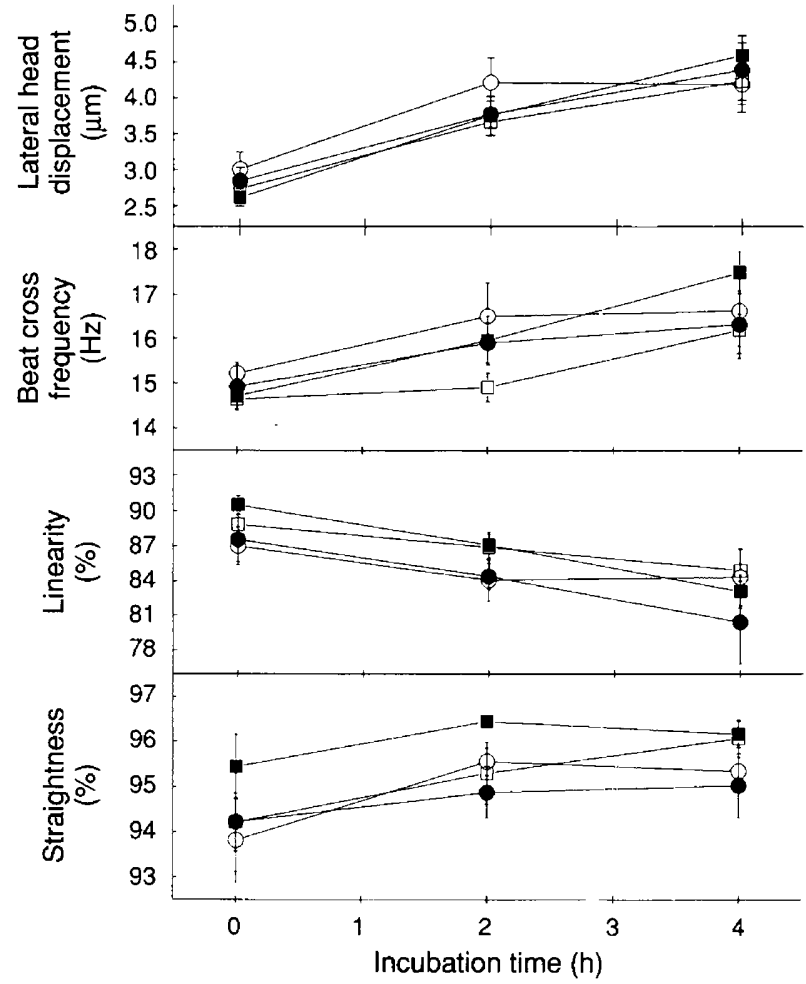

Fig. 2. Effect of oviductal fluid on four velocity parameters of sperm motility (mean \pm SEM). Spermatozoa were incubated for 0,2 or $4 \mathrm{~h}$ in $40 \%$ oviductal fluid collected from ampullary (squares) or isthmic (circles) regions from three cows during luteal (open) or nonluteal (closed) cycle stages. Spermatozoa were assessed by the HamiltonThorn motion analyser for lateral head displacement, beat cross frequency, linearity and straightness. See Table 2 for list of significant differences observed.

Thus, incubation in isthmic nonluteal oviductal fluid caused a decrease in several types of sperm velocity, as well as linearity and straightness, compared with ampullary oviductal fluid.

Incubation of spermatozoa with $40 \%$ oviductal fluid assessed the ability of oviductal fluid to facilitate both sperm capacitation and the acrosome reaction. By $2 \mathrm{~h}$, there was a significant increase $(P<0.0024)$ in the percentage of acrosomereacted spermatozoa for isthmic nonluteal oviductal fluid (Fig. 4). This trend continued throughout incubation, so that at $6 \mathrm{~h}$, spermatozoa incubated in isthmic nonluteal oviductal fluid acrosome reacted at a rate of $241 \%$ of control spermatozoa $(P=0.0004$ compared with ampullary nonluteal and isthmic luteal incubations). Incubation in the other three oviductal fluid types caused sperm acrosome reactions at rates between 156 and $180 \%$ of control.

When acrosome-reacted live and acrosome-reacted dead spermatozoa were assessed, no statistical significance was noted between the oviductal fluid treatments (data not shown). Acrosome-reacted live spermatozoa ranged from $100-120 \%$ of control at $\mathrm{Oh}$ to $200-250 \%$ of control at $4 \mathrm{~h}$, and most acrosome-reacted live spermatozoa were found following incubation in ampullary nonluteal oviductal fluid. Acrosomereacted dead spermatozoa were present at $95-115 \%$ of control at $\mathrm{Oh}$ and $105-150 \%$ of control at $4 \mathrm{~h}$. The maximum number 


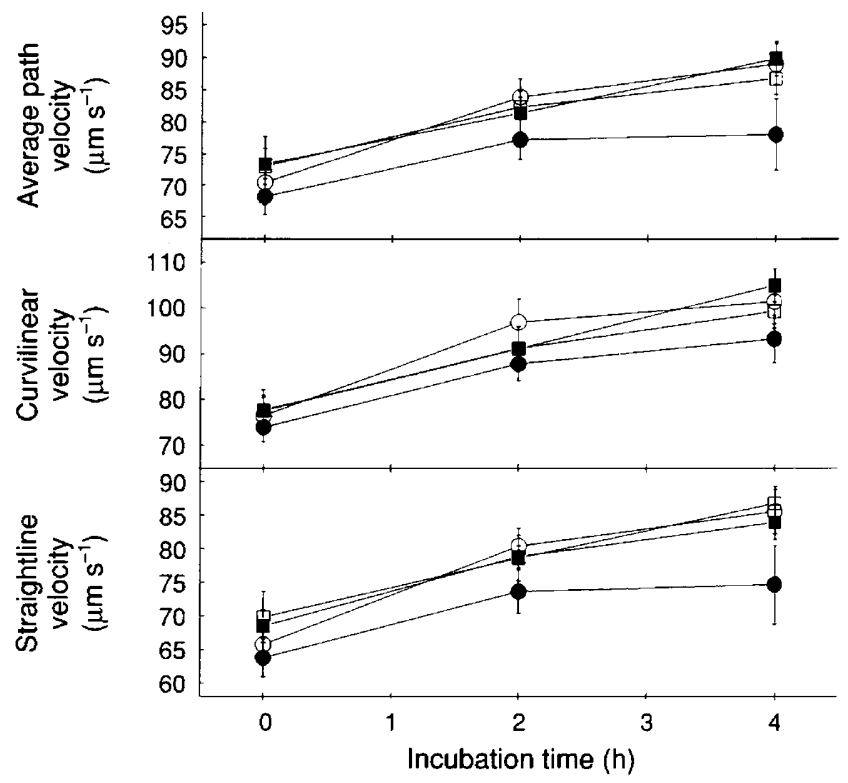

Fig. 3. Effect of oviductal fluid on three velocity parameters of sperm motility (mean \pm SEM). Spermatozoa were incubated for 0,2 or $4 \mathrm{~h}$ in $40 \%$ oviductal fluid collected from ampullary (squares) or isthmic (circles) regions from three cows during luteal (open) or nonluteal (closed) cycle stages. Spermatozoa were assessed by the HamiltonThorn motion analyser for average path velocity, curvilinear velocity and straightline velocity. See Table 2 for list of significant differences observed.

of acrosome-reacted dead spermatozoa was found after incubation in isthmic nonluteal oviductal fluid for $4 \mathrm{~h}$.

In vitro fertilization of bovine ova was highest $(88.7 \%)$ after incubation of spermatozoa with $40 \%$ ampullary nonluteal oviductal fluid (Fig. 5). Both region and stage effects were noted. Incubation of spermatozoa with ampullary nonluteal oviductal fluid resulted in a significantly greater percentage of fertilized oocytes $(P<0.05)$ than did incubation in ampullary luteal or isthmic nonluteal oviductal fluid.

Mean total concentrations of glycosaminoglycan in oviductal fluid were $0.88 \pm 0.05 \mathrm{mg} \mathrm{ml}^{-1}$ for the ampulla and $0.77 \pm 0.07 \mathrm{mg} \mathrm{ml}^{-1}$ the isthmus ( $n=4$ cows). No significant differences in total glycosaminoglycans were detected among types of oviductal fluid (data not shown).

\section{Discussion}

Treatment with oviductal fluid did not affect sperm viability as assessed by staining techniques. The increase observed in the percentage of acrosome-reacted spermatozoa was not therefore a result of acrosome lysis following cell death. Viability did not differ between oviductal fluid-treated and nontreated controls, or between regions, or stages for oviductal fluid, or incubation times used for treatment.

Incubating buil spermatozoa in whole oviductal fluid (isthmic plus ampullary) increased linearity and vigorous motility, but decreased lateral head displacement and curvilinear velocity, compared with untreated spermatozoa (McNutt et al., 1994). In the present study, we observed that the percentage of motile
Table 2. Statistically significant differences in sperm motility parameters after incubation in isthmic (I) or ampullary (A) oviductal fluid collected during luteal (L) or nonluteal (NL) oestrous cycle stages

\begin{tabular}{|c|c|c|c|}
\hline Parameter & $\begin{array}{l}\text { Incubation } \\
\text { time }\end{array}$ & $\begin{array}{l}\text { Incubation } \\
\text { fluid }\end{array}$ & $P$ value \\
\hline Lateral head displacement & $\begin{array}{l}\text { Oh } \\
2 \mathrm{~h}\end{array}$ & $\begin{array}{c}A \mathrm{~L}>\mathrm{ANL} \\
\mathrm{I}>\mathrm{A} \\
\mathrm{IL}>\mathrm{AL} \\
\mathrm{I} \mathrm{L}>\mathrm{INL}\end{array}$ & $\begin{array}{l}0.028^{*} \\
0.034 \\
0.021 \\
0.023^{*}\end{array}$ \\
\hline Beat cross frequency & $2 \mathrm{~h}$ & $\mathrm{I} L>A \mathrm{~L}$ & 0.031 \\
\hline Linearity & $2 \mathrm{~h}$ & $\begin{array}{c}A>I \\
A L>I L \\
A N L>I N L\end{array}$ & $\begin{array}{l}0.005 \\
0.024^{*} \\
0.049^{*}\end{array}$ \\
\hline Straightness & $2 \mathrm{~h}$ & $\begin{array}{l}\text { A NL > A L } \\
\text { A NL > I NL }\end{array}$ & $\begin{array}{l}0.043^{*} \\
0.028^{*}\end{array}$ \\
\hline & $4 \mathrm{~h}$ & $A>I$ & 0.051 \\
\hline Path velocity & $2 \mathrm{~h}$ & $\begin{array}{c}\mathrm{L}>\mathrm{NL} \\
\mathrm{I} \mathrm{L}>\mathrm{I} \mathrm{NL}\end{array}$ & $\begin{array}{l}0.043 \\
0.021 *\end{array}$ \\
\hline & $4 \mathrm{~h}$ & $\begin{array}{c}\text { A NL }>\text { I NL } \\
I L>I N L\end{array}$ & $\begin{array}{l}0.033^{*} \\
0.021^{*}\end{array}$ \\
\hline Curvilinear velocity & $2 \mathrm{~h}$ & $\begin{array}{l}\mathrm{L}>\mathrm{NL} \\
\mathrm{I} \mathrm{L}>\mathrm{AL} \\
\mathrm{I} \mathrm{L}>\mathrm{INL}\end{array}$ & $\begin{array}{l}0.046 \\
0.038^{*} \\
0.015^{*}\end{array}$ \\
\hline Straight line velocity & $\begin{array}{l}2 \mathrm{~h} \\
4 \mathrm{~h}\end{array}$ & $\begin{aligned} & I \mathrm{~L}>\mathrm{INL} \\
& \mathrm{I} \mathrm{L}>\mathrm{INL} \\
& \mathrm{ANL}>\mathrm{INL}\end{aligned}$ & $\begin{array}{l}0.020^{*} \\
0.023^{*} \\
0.030^{*}\end{array}$ \\
\hline
\end{tabular}

*Pairwise comparison only (stage within region or region within stage).

See Figs 2 and 3 for graphical representation of data.

spermatozoa, as well as the three velocity parameters measured (path, curvilinear and straightline velocities), were lowest after incubation in isthmic nonluteal oviductal fluid versus ampullary fluid. These findings may be related to earlier observations that spermatozoa are quiescent in the isthmus before fertilization (Suarez et al., 1990; reviewed by Ellington, 1991). Hunter and Wilmut (1984) proposed that spermatozoa may reside in a quiescent state in the bovine isthmus for up to $20 \mathrm{~h}$ before fertilization. Moreover, Cooper et al. (1979) noted reversible, depressed motility of spermatozoa in the lower oviduct of rabbits, and Suarez (1987) reported inhibition of flagellar movement in mouse oviducts, which may be a factor in detaining spermatozoa in the isthmus, and the creation of a sperm reservoir.

The greater velocities of spermatozoa incubated in ampullary oviductal fluid, as well as their increased linearity and straightness, suggest accelerated progressive sperm movement. Because spermatozoa exposed to ampullary oviductal fluid must move toward the ovum and generate force to penetrate the zona, their stimulated motility in this region is not unexpected.

Hyperactive motility of spermatozoa of many mammals may be associated with regulation of sperm transport in the oviduct (Suarez, 1987) or penetration of the zona pellucida (Fraser and Quinn, 1981; Fleming and Yanagimachi, 1982). Common accepted parameters of hyperactivation are decreased progressive movement (decreased linearity) and increased bending of the flagellum midpiece (increased lateral head movement) 


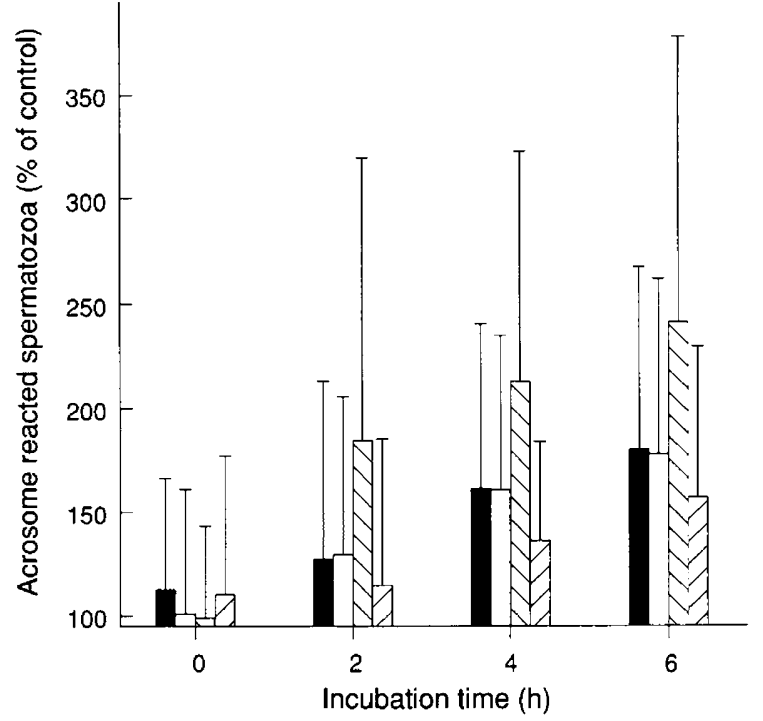

Fig. 4. Effect of oviductal fluid on the ability of spermatozoa to undergo the acrosome reaction (mean \pm SEM). Spermatozoa were incubated for $0,2,4$ or $6 \mathrm{~h}$ in $40 \%$ oviductal fluid collected from ampullary or isthmic regions from 13 cows during luteal or nonluteal cycle stages (ampullary non-luteal, $\mathbf{\square}$; ampullary luteal, $\square$; isthmic

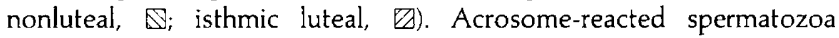
were assessed microscopically as the number of acrosome-reacted spermatozoa per 100 spermatozoa counted. This value was divided by the number of acrosome-reacted spermatozoa per 100 counted in control samples for the same incubation time. Significant differences were observed at: $2 \mathrm{~h}$, isthmic nonluteal $>$ ampullary nonluteal $(P=0.0024)$, isthmic nonluteal $>$ isthmic luteal $(P=0.0004) ; 4 \mathrm{~h}$, isthmic nonluteal $>$ ampullary nonluteal $(P=0.0004)$, isthmic nonluteal $>$ isthmic luteal $(P=0.0004) ; 6 \mathrm{~h}$, isthmic noniuteal $>$ ampullary nonluteal $(P=0.0004)$, isthmic nonluteal $>$ isthmic luteal $(P=0.0004)$.

during vigorous movement. In terms of these parameters, our results do not support the notion of hyperactivation of bovine spermatozoa following incubation with ampullary oviductal fluid. However, no quantitative description of hyperactivation has been accepted for bovine spermatozoa, and McNutt et al. (1994) identified subpopulations of bovine spermatozoa that exhibit more classic hyperactivation characteristics. McNutt et al. (1994) analysed bovine spermatozoa incubated with whole oviductal fluid for $0-4 \mathrm{~h}$ by computer-assisted automation identical to that used in the present study. Threedimensional plots of curvilinear velocity versus lateral head displacement versus frequency showed that 'hyperactive' spermatozoa were found to constitute a smaller percentage (16\%) of the total spermatozoa population, compared with untreated control spermatozoa. A similar subpopulation of hyperactivated spermatozoa may have been present among those analysed in this study, although this was not examined.

In the present study, the number of acrosome reactions was high for spermatozoa incubated in isthmic nonluteal oviductal fluid, even at $2 \mathrm{~h}$. The absence of differences in osmolality and $\mathrm{pH}$ among the $40 \%$ oviductal fractions precludes nonspecific acrosome reactions as a cause of this. These data therefore support the concept of the oviduct isthmus as a sperm reservoir, which provides a population of capacitated, acrosome-reacted spermatozoa at the time of ovulation. Smith

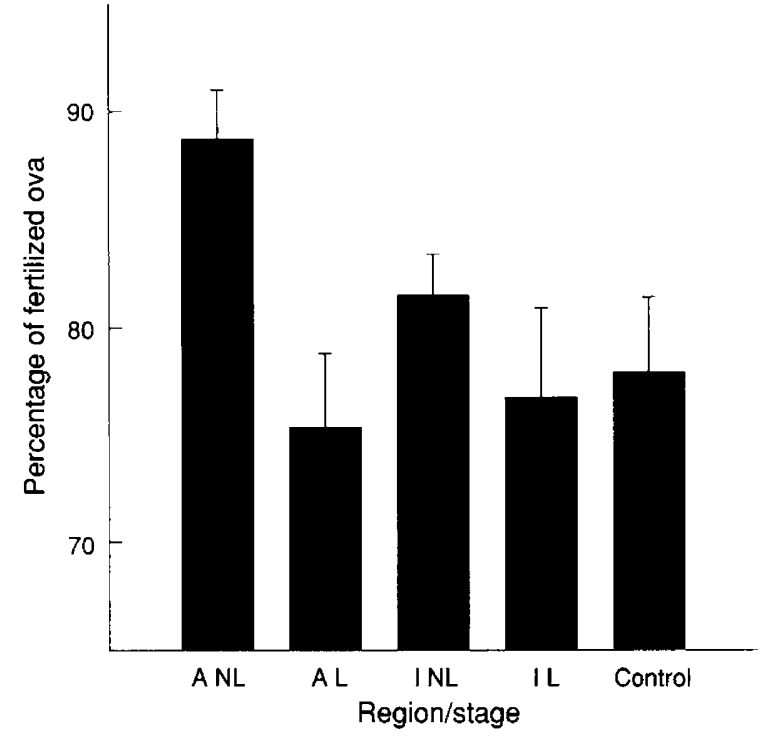

Fig. 5. Effect of oviductal fluid on sperm fertilizing ability (mean \pm SEM). Spermatozoa were incubated for $5 \mathrm{~h}$ in $40 \%$ oviductal fluid collected from ampullary (A) or isthmic (I) regions from three cows during luteal $(\mathrm{L})$ or nonluteal $(\mathrm{NL})$ cycle stages. Fertilizing ability was assessed as the percentage of ova fertilized after $16-18 \mathrm{~h}$ incubation with spermatozoa. Significant differences were observed as follows: ampullary nonluteal $>$ isthmic nonluteal $(P=0.041)$, ampullary nonluteal $>$ ampullary luteal $(P=0.009)$.

and Yanagimachi (1989) reported that the hamster oviduct apparently controls the timing of sperm capacitation to synchronize the state of the spermatozoa with ovulation, thereby maximizing the chances of fertilization. The isthmic environment may serve to facilitate capacitation and the acrosome reaction to prepare a reservoir, or population of spermatozoa, available for gradual release to fertilize the ovum. As such, the isthmus may limit the number of functionally competent spermatozoa, thus reducing the possibility of polyspermy.

The greatest ovum fertilization rate occurred using spermatozoa incubated with ampullary nonluteal fluid. These results suggest that ampullary oviductal fluid may further prepare spermatozoa released from the isthmus to achieve maximal fertilization rates at the site at the time when the ovum is present.

Cyclic variations in the composition of bovine regional oviductal fluid are evident. A combination of factors in the oviduct probably optimizes the preparation of spermatozoa for fertilization. Higher calcium concentrations were found in isthmic nonluteal oviductal fluid compared with isthmic luteal or ampullary nonluteal oviductal fluid (Grippo et al., 1992). High calcium concentrations may increase the occurrence of the acrosome reaction in spermatozoa incubated in isthmic nonluteal oviductal fluid. Increased concentrations of lysophosphatidylcholine were also found in ampullary oviductal fluid collected during the nonluteal stage (Grippo et al., 1994). This fusogenic lysophospholipid may service to maximize the number of acrosome-reacted spermatozoa in the ampulla at fertilization. Oestrus-associated protein is present in oviductal fluid primarily during the nonluteal stage (Gerena and Killian, 1990) and in a higher concentration in ampullary-derived fluid than in isthmic fluid (Wegner and Killian, 1992). Downloaded from Bioscientifica.com at 04/26/2023 12:43:12PM 
Oestrus-associated protein is associated with the sperm membrane, and stimulates increased capacitation and fertilization of bovine spermatozoa (King et al., 1994).

Proteins and proteoglycans produced by the isthmus at oestrus are believed to play a major role in the abilities of conditioned medium from bovine explants to capacitate spermatozoa (Anderson and Killian, 1994). These authors also reported higher concentrations of glycosaminoglycans in isthmic/oestrus conditioned medium, compared with ampullary/oestrus or isthmic/luteal media. In the present study, differences between concentrations of glycosaminoglycans in oviductal fluid from the two regions or the two stages were not observed, suggesting that they are not solely responsible for observed differences in sperm acrosome reaction, as proposed by Parrish et al. (1989). The disparity in concentrations of glycosaminoglycans noted in oviductal fluid compared with that of the conditioned medium may be due to sample handling. In the conditioned medium preparations, molecules of $<10 \mathrm{kDa}$ (including free glycosaminoglycans) were excluded, and all preparations were standardized against protein concentration. Both free glycosaminoglycans and proteoglycans were measured, as well as smaller biological molecules that may affect sperm motility, capacitation and the acrosome reaction. It is likely that many biologically active molecules and biochemical reactions could account for the observed increased fertilization of bovine ova by bovine spermatozoa in the ampullary environment at the time of ovulation.

The results of this study separate oviductal regional and oestrous cycle stage effects on sperm physiology. We demonstrated that oviductal fluid collected from the isthmus during the nonluteal stage, although lowering sperm motility, optimizes the ability of spermatozoa to undergo the acrosome reaction, without diminishing their viability. These effects may serve to increase the number of spermatozoa prepared to fertilize the ovum in the ampulla during the nonluteal stage.

The assistance of T. McNutt, A. Hines, D. Zaczek, O. Raezer and the laboratory staff of the Dairy Breeding Research Center is greatly appreciated. Y. Akin and S. Arnold, PSU Statistics Consulting, assisted with the statistical design and analysis. The authors thank P. Olds-Clarke for assistance with sperm motion analyses. This work was supported by USDA Grants 89-37240-4771 and 91-37203-6554.

\section{References}

Anderson SH and Killian GJ (1994) Effect of oviductal conditioned medium macromolecules on bovine sperm motion and capacitation Biology of Reproduction 51 795-799

Bavister BD (1981) Substitution of a synthetic polymer for protein in a mammalian gamete culture system Journal of Experimental Zoology 217 $45-51$

Bavister BD, Leibfried ML and Lieberman G (1983) Development of preimplantation embryos of the golden hamster in a defined medium Biology of Reproduction 28 235-247

Boice ML, Geisert RD, Blair RM and Verhage HG (1990) Identification and characterization of bovine oviductal glycoproteins synthesized at estrus Biology of Reproduction 43 457-465

Buhi WC, Vallet JL and Bazer FW (1989) De novo synthesis and release of polypeptides from cyclic and early pregnant porcine oviductal tissue in explant culture Journal of Experimental Zoology 252 79-88
Cooper GW, Overstreet JW and Katz DF (1979) The motility of rabbit spermatozoa recovered from the female reproductive tract Gamete Research 2 35-42

Ellington JE (1991) The bovine oviduct and its role in reproduction: a review of the literature Cornell Veterinarian 81 313-328

First NL and Parrish JJ (1987) In vitro fertilization of ruminants Journal of Reproduction and Fertility Supplement 34 151-165

Fleming AD and Yanagimachi R (1982) Fertile life of acrosome-reacted guinea pig spermatozoa. Journal of Experimental Zoology 220 109-115

Fraser LR and Quinn PJ (1981) A glycolytic product is obligatory for initiation of sperm acrosome reaction and whiplash motility required for fertilization in the mouse Journal of Reproduction and Fertility $6125-35$

Gerena RL and Killian GJ (1990) Electrophoretic characterization of proteins in oviduct fluid of cows during the estrous cycle Journal of Experimental Zoology 256 I13-120

Grippo AA, Henault MA, Anderson SH and Killian G) (1992) Cation concentrations in fluid from the oviduct ampulla and isthmus of cows during the estrous cycle Journal of Dairy Science 75 58-65

Grippo AA, Anderson SH, Chapman DA, Henault MA and Killian GJ (1994) Cholesterol, phospholipid and phospholipase activity of ampullary and isthmic fluid from the bovine oviduct Journal of Reproduction and Ferility 102 $87-93$

Hunter RHF and Wilmut I (1984) Sperm transport in the cow: peri-ovulatory redistribution of viable cells within the oviduct Reproduction and Nutrition Development 24 597-608

Kavanaugh JF and Killian GJ (1988) Bovine oviductal cannulations Journal of Investigative Surgery 1 201-208

Kavanaugh JF, Grippo AA and Killian GJ (1992) Cannulation of the bovine ampullary and isthmic oviduct Journal of Investizative Surgery 5 11-17

Killian GJ, Chapman DA, Kavanaugh JF, Deaver DR and Wiggin HB (1989) Changes in phospholipids, cholesterol and protein content of oviduct fluid of cows during the oestrous cycle Journal of Reproduction and Fertility 86 419-426

King RS, Anderson SH and Killian GJ (1994) Effect of bovine oviductal estrus-associated protein on the ability of sperm to capacitate and fertilize oocytes Journal of Andrology 15 468-478

Kubajak CL and Ax RL (1985) Measurement of glycosaminoglycans in ovarian follicular fluid using alcian blue dye. In Proceedings of the Fifth Biennial Ovarian Workshop pp 497-501 Eds DO Toft and RJ Ryan. Champaign, IL

Leese HJ (1988) The formation and function of oviduct fluid Journal of Reproduction and Fertility 82 843-856

Lenz RN, Ax RL, Grimek HJ and First NL (1982) Proteoglycan from bovine follicular fluid enhances an acrosome reaction in bovine sperm Biochemical and Biophysical Research Communication 106 1092-1098

McNutt TL and Killian GJ (1991) Influence of bovine follicular and oviduct fluids on sperm capacitation in vitro Journal of Andrology 12 244-252

McNutt TL, Olds-Clarke P, Way AL, Suarez SS and Killian GJ (1994) Effect of follicular or oviductal fluids on movement characteristics of bovine sperm during capacitation in vitro Journal of Andrology 15 328-336

Malayer JR, Hansen PJ and Buhi WC (1988) Secretion of proteins by cultured bovine oviducts collected from estrus through early diestrus Journal of Experimental Zoology 248 345-353

Mastroianni L, Beer F, Shah U and Clewe TH (1961) Endocrine regulation of oviduct secretions in the rabbit Endocrinology 68 92-100

Parrish JJ, Susko-Parrish JL, Winer MA and First NL (1988) Capacitation of bovine sperm by heparin Biology of Reproduction 38 1171-1180

Parrish JJ, Susko-Parrish JL, Handrow RR, Sims MM and First NL (1989) Capacitation of bovine spermatozoa by oviduct fluid Biology of Reproduction 40 1020-1025

Restall BJ (1966) The Fallopian tube of the sheep. II. The influence of progesterone and oestrogen on the secretory activities of the Fallopian tube Australian Journal of Biology Science 19 187-197

SAS (1988) SAS User’s Guide: Statistics Version 5 SAS Institute Incorporated, Cary, North Carolina

Shaffer HE and Almquist JO (1948) Staining of bovine spermatozoa with an eosin-aniline blue staining mixture Journal of Dairy Science 31677

Sirard MA, Parish JJ, Ware CB, Leibfried-Rutledge ML and First NL (1988) The culture of bovine oocytes to obtain developmentally competent embryos Biology of Reproduction 39 546-552.

Smith TT and Yanagimachi R (1989) Capacitation status of hamster spermatozoa in the oviduct at various times after mating Journal of Reproduction and Fertility 86 255-261

Suarez SS (1987) Sperm transport and motility in the mouse oviduct: observations in situ Biology of Reproduction 36 203-210

Downloaded from Bioscientifica.com at 04/26/2023 12:43:12PM 
Suarez SS, Drost M, Redfern K and Gottlieb W (1990) Sperm motility in the oviduct. In Fertilization in Mammals pp 11-24 Eds BD Bavister, J Cummins and ERS Roldan. Serono Symposia, Norwell

Verhage HG, Boice ML, Mavrogianis P, Donnelly K and Fazleabas AT (1989) Immunological characterization and immunocytochemical localization of oviduct-specific glycoproteins in the baboon (Papio anubis) Endocrinology $124 \quad 2464-2472$
Way AL, Henault MA and Killian GJ (1995) Comparison of four staining methods for evaluating acrosome status and viability of ejaculated and cauda epididymal bull spermatozoa Theriogenology 43 1301-1316

Wegner C and Killian GJ (1992) Origin of estrus-associated glycoproteins in bovine oviductal fluid Molecular Reproduction and Development 95 841-854

Whiteman $\mathbf{P}$ (1973) The quantitative measurement of alcian blueglycosaminoglycan complexes Biochemistry Journal $131343-350$ 